\title{
Teaching Evolution While Aiming at the Cautious Middle
}

\author{
K. Kampourakis: Understanding Evolution. Cambridge University \\ Press, 2014, ISBN: 9781107610200, 270 pp, \$34.99 (Paperback)
}

\section{Massimo Pigliucci}

(C) Springer Science+Business Media Dordrecht 2015

As astounding as it sounds, especially to people outside of the USA (and the Middle East, and much of Africa), $13 \%$ of US high school teachers actively advocate creationism and so-called intelligent design theory in their classrooms; another $28 \%$ does the right thing and teaches evolution, but a whopping $60 \%$ falls in the middle: These teachers accept evolutionary theory (though they may be fuzzy on the details), and yet do not teach it in their classrooms, in order to avoid "the controversy" (Berkman and Plutzer 2010). It is largely at this $60 \%$, and to interested undergraduate and graduate students, that Kampourakis' new book is aimed.

As the author quickly acknowledges, there are plenty of good books on evolution out there: from introductions aimed at the general public (Coyne 2009) to sophisticated textbooks (Futuyma 2013), from philosophical analyses (Ruse 2003) to discussions of the so-called evolution-creation controversy (Pigliucci 2002), and many, many more. So why another one, other than because - as the ancient Romans were fond of saying-repetita iuvant (to repeat does good)? Because, argues Kampourakis, contra to a widespread assumption among educators, the biological theory of evolution is actually counterintuitive, and if not properly taught, it immediately runs into incomprehension and generates conceptual confusion.

The author is not as naive as to suggest that the only, or indeed even the primary, reason why we still have a creation-evolution debate 90 years after the scopes trial and more than a century and a half after the publication of the Origin of Species is that people are confused about what the theory actually says. Surely social and especially ideological forces, particularly religious fundamentalism and its connection with extreme right-wing politics, get a lot of the blame here. But very good books on that aspect of the problem have already come out, and Kampourakis has identified a lacuna in the recent literature: It is hard to find a clear compelling explanation of why exactly evolution is so difficult to understand for so many people. The chief goal of his book, then, becomes to fill this lacuna. This is attempted in six chapters that cover how we know what we know about evolution (i.e., that it is a fact), why there is religious resistance to accepting the idea, what

M. Pigliucci $(\bowtie)$

Department of Philosophy, The City College of New York, New York, NY, USA

e-mail: massimo@platofootnote.org 
the major conceptual (as distinct from ideological) obstacles to acceptance are, the concept of common ancestry, and the mechanisms of evolutionary change (not just natural selection, but also the stochastic aspects of the process).

Chapter 4 of the book stands apart from the rest, in my mind, and for interesting reasons. The title of the chapter is rather self-explanatory: "Charles Darwin and the Origin of Species: A historical case study of conceptual change," and it may superficially look as yet another glorifying exegesis of one of the best known (and, admittedly, most important) books in the intellectual history of humanity. But Kampourakis' writing here does a rather different, and very pertinent thing: It is a careful analysis of how Darwin's theory itself "evolved" (in the sense of developed, of course) over his lifetime.

The most interesting part of this analysis begins on p. 108, when Kampourakis delves into a conceptual dissection of the Darwinian theory. Figure 4.3 in the book (p. 113) is a compelling summary of the major phases of the evolution of Darwin's thinking, which the author divides into three phases: From his 1835 visit to the Galapagos Island to 1839, by which time Darwin already had an outline of his theory of natural selection, he thought in terms of perfect adaptations, essentially still in the mold of Paley-style natural theology, but with an increasingly naturalistic twist.

Things began to change in the years leading to 1842, when Darwin wrote his Sketch of the Theory, continuing into 1854 and the completion of his study on barnacles. During this time frame, Darwin still thought of adaptations as perfect, but in a more "limited" fashion, so to speak. Finally, from his 1857 abstract of the theory, sent to his colleague and friend Asa Gray, to the actual publication of the Origin in 1859, Darwin shifted to a more modern consideration of adaptations as relative to specific environments and certainly not perfect in any meaningful sense of the term.

But perhaps my favorite figure in the entire book is 4.4 (p. 120), a flow chart of the conceptual foundations of the arguments presented by Darwin in the Origin. One of the most obvious things that jump to the reader's attention in the diagram is the extensive use made by Darwin of arguments from analogy: the analogy between artificial and natural selection, between the struggle for existence in human societies (Malthus) and the struggle for existence in nature, and between the division of labor in human societies (Adam Smith) or the physiological division of labor in living organisms (Milne-Edwards) and ecological specialization causing divergence among species. If this sort of thing doesn't make clear how Darwin developed his argument, I don't know what will.

There are a number of similar gems scattered throughout Kampourakis' book. For instance, on p. 52, we find a table (2.1) that presents a comparative overview of the positions taken by three prominent evolutionary biologists-Richard Dawkins, Stephen Gould, and Conway Morris - on the relation between science and religion, which itself is, of course, at the core of the creation-evolution wars. It will be good for teachers and students alike to find out that Dawkins-style atheism is by far not the only (or perhaps even the most common) position on the question adopted by biologists, and I say this quite regardless of the fact that I find myself somewhere between Gould's agnosticism and Dawkins' atheism and certainly far from Morris' religiosity.

Just a couple of pages down, we find table 2.2, a synopsis of three major ways of grounding one's beliefs: causal, justificational, and epistemic. Kampourakis explains the differences among them by way of a simple example involving his wife and the dinner he believes she has prepared for him: "I smell my favorite food and I believe that my wife is cooking it" is an example of causal grounding of his belief; by contrast, "I smell my favorite food and my wife told me this morning that she would do it" is an instance of justificational belief; finally, "I smell my favorite food and I saw my wife in the kitchen 
cooking it" is a type of epistemic explanation for the belief. (As a side note, it would have been refreshing if the author had put himself in the role of cook, thus challenging the cultural stereotype, but this is obviously not a substantive criticism.)

There are examples in the book that I am not quite so fond of, for instance figure 3.6 (p. 85), where Kampourakis presents an imaginary phylogenetic diagram featuring humanmade objects such as airplanes, ships, and so forth. Although he hastens to write in the caption that "this depiction is, of course, incorrect as these artifacts have independent origins," I'm afraid students inclined toward intelligent design will gloss over that caveat and persist in their anthropomorphic way of seeing things.

Then again, the comparison-in figure 5.4 (p. 136) between human genealogies and biological phylograms is one that I think is surprisingly underutilized in the teaching of evolution, and it ought to immediately clear things up when students ask questions along the lines of: "if we come from apes, how is it that both we and the chimpanzees are still alive?" The answer, of course, is the same as if one were asking how is it possible that my cousin is alive at the same time as me, even though we share common ancestors.

Kampourakis does not shy from the treatment of more sophisticated issues in evolutionary biology, or even from using a modicum of technical jargon. The book includes discussions of symplesiomorphies and synapomorphies, of the difference between genetic drift and genetic draft, as well as of the distinction between adaptation and exaptation. It also clearly shows (by now well known, but always spectacularly clear) examples of transitional fossils, like those marking the evolution of whales (fig. 5.17, p. 153), thus answering yet another persistent, if misguided, creationist question ("if evolution is a gradual process, where are all the intermediaries?").

Figure 5.21 (p. 160) very clearly explains to the reader why it is a misconception to think of individuals (as opposed to populations) as the units of evolution, but it also introduces the evo-devo (evolution of development) perspective, thus bringing the reader up to speed with current thinking in the field.

The discussion of modes of speciation (pp. 191-200) will not make some more orthodox evolutionary biologists too happy, because it presents the difference between sympatric and allopatric speciation as a continuum, rather than a simple dichotomy, and because it introduces students to the still somewhat controversial idea of species selection. But I think Kampourakis is exactly right on both counts, and teachers and students do need to be exposed to cutting edge ideas in science, even ideas that may eventually be rejected as inviable. Too often we present science as a monolithic and unchangeable body of results, indirectly reinforcing the comparison with scriptures and the misperception that science is just another belief system.

The book concludes by zooming out, so to speak, into broader conceptual space, presenting the reader with a discussion of evolution as a theory within the context of what, exactly, makes for a good scientific theory to begin with. Kampourakis draws a crucial distinction between what a theory-any theory, not just evolution-cannot explain versus what it has not explained yet. The Darwinian theory of evolution cannot and will not explain, say, the origin of life, because by definition before life appeared, there were no populations of organisms capable of variation and inheritance, the fundamental conditions for evolution to take place. That job, therefore, belongs to biophysics rather than evolutionary biology, and the common insistence to the contrary on the part of creationists betrays a fundamental misunderstanding of the scope of scientific theorizing.

However, there are also biological facts well within the potential purview of Darwinian explanations that have not, so far, actually been explained (and perhaps never will be). Take, for instance, the so-called Cambrian explosion, the (geologically) rapid 
diversification of myriad new animal forms that eventually gave rise to most of the phyla we know today. Plenty of accounts have been proposed for the phenomenon, but there hardly is a consensus within the pertinent epistemic community (i.e., evolutionary biologists and paleontologists). This, however, cannot be impugned as an example of "failure" of the theory, no more than, say, the fact that quantum mechanics and general relativity give incompatible answers about the physics of black holes should be taken as a good reason to reject either of those physical theories. Scientific theories are dynamic, ever changing, perpetually incomplete and open to revision human constructs to make sense of the world. The more the public at large understands this, the better off we will be, and books like Kampourakis' certainly make a valuable contribution to nudging us into that desirable direction.

\section{References}

Berkman, M., \& Plutzer, E. (2010). Evolutionism, creationism, and the battle to control America's schools. New York: Cambridge University Press.

Coyne, J. A. (2009). Why evolution is true. New York: Viking Adult.

Futuyma, D. J. (2013). Evolution. Sunderland: Sinauer.

Pigliucci, M. (2002). Denying evolution: Creationism, scientism, and the nature of science. Sunderland: Sinauer.

Ruse, M. (2003). Darwin and design: Does evolution have a purpose? Cambridge, MA: Harvard University Press. 